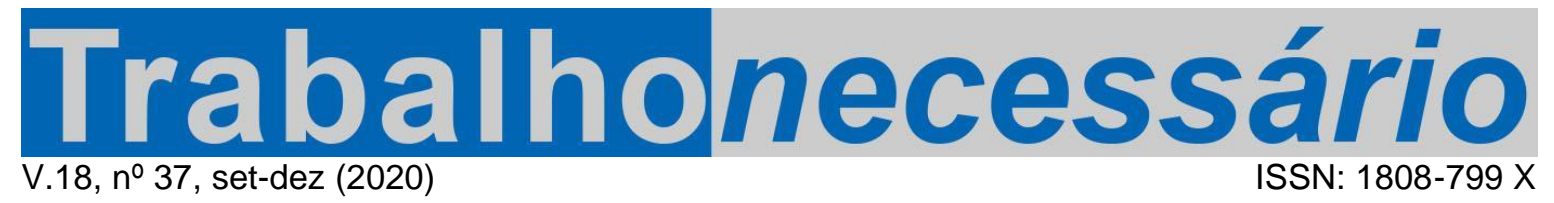

\title{
TECNOLOGIAS DIGITAIS, TRABALHO DOCENTE E TEMPOS/ESPAÇOS DE APRENDIZAGENS NA AMAZÔNIA ${ }^{1}$
}

\author{
Maria Sueli Corrêa dos Prazeres ${ }^{2}$ \\ Ilda Gonçalves Batista ${ }^{3}$
}

\begin{abstract}
Resumo
O artigo analisa o uso de dispositivos móveis por docentes nas escolas de ensino médio no município de Cametá/PA e as mudanças ocorridas nas relações/espaço-tempo, referenciada pelo materialismo histórico. Conclui-se que o uso das tecnologias digitais na escola converge num duplo sentido (pessoal e pedagógico) e retroage em desdobramentos favoráveis e, ao mesmo tempo, desfavoráveis ao ensino e a prática docente, construindo uma "nova" dinâmica que possibilita outras relações tecidas no espaçotempo virtual/real relacionada, especialmente, ao trabalho docente.
\end{abstract}

Palavras-chave: Educação; Tecnologias digitais móveis; Trabalho docente.

\section{TECNOLOGÍAS DIGITALES, TRABAJO DOCENTE Y TIEMPO / ESPACIOS DE APRENDER EN LA AMAZONIA}

\section{Resumen}

El artículo analiza el uso de dispositivos móviles por parte de los maestros en las escuelas secundarias del municipio de Cametá / PA y los cambios que ocurrieron en las relaciones/ espacio-tiempo, a los que hace referencia el materialismo histórico. Se concluye que el uso de tecnologías digitales en la escuela converge en un doble sentido (personal y pedagógico) y retroactivo en desarrollos favorables y, al mismo tiempo, desfavorable para la enseñanza y la práctica docente, construyendo una dinámica "nueva" que hace posible otras relaciones entrelazadas en espacio / tiempo virtual / real relacionado, especialmente, con el trabajo docente.

Palabras clave: Educación; Tecnologías digitales móviles; Trabajo docente.

\section{DIGITAL TECHNOLOGIES, TEACHING WORK AND LEARNING TIMES/SPACES IN AMAZÔNIA}

\section{Abstract}

The article analyzes the use of mobile devices by teachers in high schools in the municipality of Cametá / PA and the changes that occurred in the relations / space-time, referenced by historical materialism. It is concluded that the use of digital technologies in the school converges in a double sense (personal and pedagogical) and retroactive in favorable developments and, at the same time, unfavorable to teaching and teaching practice, building a "new" dynamic that makes possible other woven relationships in virtual / real space-time related, especially, to teaching work.

Keyword: Education; Mobile digital; technologies; Teaching work.

\footnotetext{
1 Artigo recebido em 01/06/2020. Primeira avaliação em 06/06/2020. Segunda avaliação em 20/06/2020. Aprovado em 16/07/2020. Publicado em 25/09/2020.DOI: https://doi.org/10.22409/tn.v18i37.46282

${ }^{2}$ Doutora em Educação pela Universidade Estadual de Ponta Grossa (UEPG) - Paraná - Brasil. Mestre em Educação pela Universidade Federal do Pará (UFPA) - Brasil. Atualmente é docente da Universidade Federal do Pará E-mail: suelicorrea@ufpa.br. ORCID: 0000-0001-8119-6313. Lattes: http://lattes.cnpq.br/7320780651650730

${ }^{3}$ Mestre em Educação e Cultura pelo Programa de Pós-Graduação em Educação e Cultura da Universidade Federal do Pará - Brasil (PPGEDUC/UFPA - Brasil). É docente da Prefeitura Municipal de Parauapebas. amazônico. E-mail: ildagoncalves92@yahoo.com.br ORCID: 0000-0002-5745-6207. Lattes: http://lattes.cnpq.br/5408547583754911
} 


\section{Introdução}

O artigo analisa o uso das tecnologias digitais móveis por professores das escolas públicas no município de Cametá/PA e as mudanças ocorridas nas relações/espaço-tempo no cotidiano das escolas estaduais ${ }^{4}$. Parte-se do pressuposto de que a inserção das tecnologias digitais móveis se apresenta como possibilidade de alunos e professores terem acesso a formas outras de informação e comunicação na escola. Todavia, esse acesso tem-se materializado a partir de tensionamentos e contradições que ora "enriquecem", ora "empobrecem" as ações educativas em virtude das relações tecidas durante e/ou após a prática educativa.

O estudo referencia-se pelo materialismo histórico-dialético, que possibilita alcançar a realidade do objeto de pesquisa no seio da sociedade capitalista e apontar meios para transpor essa realidade. Parte-se dos problemas concretos da realidade histórico-social, pois é ela que dará subsídios para compreender a totalidade concreta do estudo, uma vez que para Marx (2008, p. 258-259) "o concreto é concreto, porque é a síntese de muitas determinações". Compreender a realidade em sua totalidade pressupõe começar a análise pelas relações mais simples até alcançar as mais complexas e, posteriormente, o todo estará envolvido em um só movimento.

O método dialético possibilitou conhecer os pressupostos ideológicos e econômicos que se escondem por trás da defesa das tecnologias digitais na sociedade, bem como os tensionamentos, as contradições, os limites e as possibilidades de mediação no contexto educacional. Revelar esse "claro-escuro de verdade e engano", a "pseudoconcreticidade" (KOSIK, 2002), é uma tarefa complexa, mas que possibilita compreender a realidade concreta do estudo sobre as tecnologias móveis e o contexto educacional, assim como visualizar a forma em que o objeto se apresenta, se transforma e como se realiza a passagem de interpretação de um fenômeno social aparente para a sua concreticidade.

O município de Cametá possui 8 escolas estaduais, distribuídas entre a área urbana e as vilas do município. Realizou-se pesquisa em uma escola pública de ensino médio, situada no espaço urbano, adotando-se como critério a escola ofertar o nível médio de ensino regular; estar situada na sede do município onde o acesso à

\footnotetext{
${ }^{4} \mathrm{O}$ artigo resulta de discussões realizadas no contexto do Curso de Mestrado em Educação e Cultura da Universidade Federal do Pará, sobre o uso de tecnologias digitais móveis nas escolas de ensino médio no município de Cametá/PA e as mudanças ocorridas nas relações/espaços-tempos. Aqui, tratase de versão revisada e ampliada.
} 
tecnologia é mais facilitado e, por último, os sujeitos terem acesso às tecnologias digitais móveis.

Para a coleta de dados utilizou-se de entrevista semiestruturada em uma escola pública de ensino médio, com oito professores da rede pública estadual no município de Cametá/PA, sendo cinco mulheres e três homens, sendo complementada pela observação no cotidiano escolar.

O texto apresenta-se dividido em três seções. Na primeira discute-se a inserção das tecnologias da informação e comunicação no campo educacional, problematizando a lógica instrumental que caracteriza o uso das tecnologias nas escolas e a possibilidade de sua superação. Na segunda seção analisa-se a possibilidade de criação de novos tempos/espaços de aprendizagem a partir da inserção das tecnologias digitais móveis. Na terceira e última seção reflete-se sobre a vivência e trabalho docente com o uso das tecnologias digitais móveis nas escolas.

\section{Tecnologias da Informação e Comunicação na educação: da lógica instrumental à possibilidade de novos tempos/espaços de aprendizagem}

Parte-se do entendimento que a tecnologia não pertence a um só indivíduo, a um grupo de pessoas, a uma comunidade, muito embora ela tenha sido apropriada, historicamente, por grupos dominantes para produzir mais-valor, mercadoria, dinheiro, ferramentas tecnológicas. Comungamos da perspectiva marxiana de que "Uma história crítica da tecnologia provaria o quão pouco qualquer invenção do século XVIII pode ser atribuída a um único indivíduo [...]. (MARX, 2013, p. 446). Para Marx, a tecnologia é resultado de processos históricos pertencentes à humanidade, sendo, portanto, projetada para satisfação de necessidades básicas e melhoria das condições de vida do homem.

Todavia, é na sociedade capitalista que, contraditoriamente, ao ser apropriada pelo capital, passa a ter a função de aumentar a produtividade, gerando mais-valia relativa. Dessa forma, a compreensão do conceito de tecnologia, na sociedade capitalista, é primordial, uma vez que a concepção mais recorrente parece ser aquela que coloca as ferramentas a serviço dos fins econômicos, em detrimento das necessidades humanas, isto é, meramente instrumental.

Assim, acredita-se que, mesmo em face de um processo em que o capital se apropria das tecnologias para explorar a força de trabalho e gerar lucro, é possível propor alternativas que possam viabilizar a apropriação dos recursos tecnológicos, a 
partir de uma concepção crítica da tecnologia. Esse processo exigirá dos sujeitos de diferentes categorias a disposição para lutar por um projeto que subsidie a classe trabalhadora para ir além da concepção ingênua das tecnologias (VIEIRA, p., 2005). Além disso, deve servir de instrumento de luta contra a lógica perversamente instrumental que vem sendo imposta pela sociedade capitalista, que objetiva "treinar" e "adaptar" as pessoas para que melhor utilizem as tecnologias na sociedade e na escola.

Uma análise à luz dos acontecimentos históricos provará que os homens, no decurso de seu desenvolvimento histórico, não aceitaram passivamente os postulados ideológicos que lhes foram impostos pela lógica do mundo invertido das mercadorias, onde as coisas e o ter se sobrepõem ao homem. Ao contrário, isso foi bastante evidenciado na célebre afirmação de Marx, que afirma ser a história de todas as sociedades que existiram até hoje, a história das lutas de classes.

Argumenta-se, então, que esse processo somente será possível por meio da luta da classe trabalhadora, já que, conhecendo a lógica do capital, seria como esperar por um milagre que o sistema permitisse qualquer forma de controle (MÉSZÁROS, 2005). A possibilidade de superação da dimensão instrumental se dará, portanto, pelo uso crítico-dialético das tecnologias na escola.

Para tanto, torna-se essencialmente importante que os usos das tecnologias nas escolas devem ser a partir das dimensões pedagógica, didática e científica, para que, realmente, possam auxiliar os sujeitos não somente na busca de informações, mas, principalmente, para transformá-las em conhecimento. Depois, os sujeitos devem formatar uma concepção dialética das tecnologias, que lhes auxilie superar os processos alienantes que os levam a perceber somente a forma-mercadoria, a máquina, o computador.

Defende-se que os sujeitos sejam incluídos no universo digital como possibilidade de acesso à informação e ao conhecimento historicamente construído, mesmo tendo clareza que em face da sociedade excludente como a capitalista, esse processo seja dificultado sobremaneira para a classe trabalhadora. Defende-se que são os próprios sujeitos, nos seus processos de luta, que devem apontar quais políticas e tecnologias são mais adequadas à sua realidade de vida e trabalho. Todavia, se são verdadeiras as assertivas de Mészáros (2011) de que a tecnologia capitalista é pensada como propósito de reprodução ampliada do capital, também são verdadeiros os movimentos históricos de resistência e de processos contra 
hegemônicos da classe trabalhadora, que luta pela garantia de direitos como a reforma agrária, a preservação ambiental, educação, saúde e tantos outros.

Partindo do pressuposto de que a tecnologia foi idealizada e construída pelo homem, que é o único que tem a capacidade de imaginar e projetar objetivamente, conforme observou Marx, Vieira Pinto (2005), buscando o caráter ontológico da tecnologia e a relação com o ser social, realiza uma análise minuciosa da essência da tecnologia, ao abordar a relação orgânica entre o homem e a natureza, e entre a técnica e o trabalho. Para o autor, a tecnologia incorpora uma dimensão ambivalente, ou seja, ela incorpora e reproduz elementos de classe e de poder, interesses e preferências culturais, mas, ao mesmo tempo, traz a dimensão dialética de possibilidade de ser o seu contrário.

Ao revelar o caráter dialético da tecnologia, o autor afirma que a tecnologia pode ser "ao mesmo tempo o esteio e a arma da dominação, na mão do senhor, e a esperança de liberdade e o instrumento para consegui-la, na mão do escravo" (VIEIRA PINTO, 2005). Isso evidencia o aspecto contraditório que envolve os processos de introdução das tecnologias na sociedade. A análise do autor indica que conceber a tecnologia apenas como uma vitória do homem sobre a natureza, acompanhada das possibilidades de satisfação das necessidades básicas, é extremamente complexo e nos remete a pensar apenas em sua suposta dimensão neutra.

Assim, analisar o conceito e a natureza da tecnologia no contexto contemporâneo é essencial, uma vez que, conforme Vieira Pinto (2005), toda tecnologia transporta um conteúdo ideológico. Como existe um interesse dos grupos dominantes em manter uma espécie de "feitiço" sobre a concepção e conteúdo das tecnologias, torna-se essencialmente importante compreender seu significado no contexto mais ampliado, a fim de lutar contra a escamoteação produzida pelo sentido ideológico dessa tecnologia.

Portanto, torna-se imprescindível estabelecer mediações para que a mercadoria capitalista, que naturalmente encaminha para o uso instrumental, seja elevada ao âmbito das suas potencialidades, sempre em direção de apontar caminhos para a superação dessa dimensão alienante no cenário da sociedade capitalista. A superação, portanto, perpassa pela mediação dialética que aponta para a superação da alienação, do modo de produção capitalista de exploração, reprodução e formatação dos sujeitos alienados ante o processo de inserção tecnológica (BUENO, 2013). 
Neste aspecto, a mediação se faz essencial, mas não a mediação que favorece os aspectos instrumentais, o uso pelo uso das ferramentas, mas aquela que atribui uma dimensão pedagógica capaz de oportunizar espaços de diálogo, reflexão, sempre em direção à possibilidade de superação da dimensão instrumental das tecnologias na escola. As análises encaminham para a constatação de que "[...] a mediação não é pelas máquinas, pelos artefatos inovadores, mas pela capacidade de problematizar, questionar e dialogar com a realidade histórica dos sujeitos (BUENO, 2013). Logo, o sentido dessa mediação deve ser aquele que priorize os sujeitos como centro do processo de mudança.

Assim, reafirma-se a defesa de que o acesso ao mundo digital deve ser qualificado, pois entende-se que não se trata apenas de garantir o acesso aos recursos tecnológicos numa perspectiva instrumentalizada. Devem ser oportunizadas condições para que os sujeitos possam se apropriar dos códigos e das diferentes linguagens do mundo digital-tecnológico, e que sem eles, torna-se impossível o acesso à informação e ao conhecimento que auxilie os sujeitos a transformar sua realidade social, criando novas formas de interação e comunicação, bem como, novos espaços/tempos de aprendizagem.

\section{Tecnologias digitais, tempo/espaços e suas inter-relações na escola}

Muito recentemente, as tecnologias da informação e comunicação deixaram o campo analógico e transformaram-se em formato digital. Sustentadas pela introdução da internet, estão associadas ao "[...] desenvolvimento de processos e atividades em escalas muito maiores do que antes, e de formas mais rápidas e poderosas" (KOBS, 2017, p. 39). Até pouco tempo atrás, elas faziam parte de um conjunto de tecnologias fixas, presas a ambientes, à fiação e a desktops, contudo, recentemente ganharam outra característica - a mobilidade ${ }^{5}$ (CORDEIRO, 2014). Mobilidade é um termo polissêmico e sistêmico que envolve todas as relações sociais e é caracterizada pelo modo como vive o homem, estando ligado à divisão social e territorial do trabalho e aos modos de produção da sociedade (BALBIM, 2016).

\footnotetext{
${ }^{5}$ Lemos (2011) destaca que podemos pensar em três dimensões fundamentais de mobilidade: a do pensamento, a física e a informacional-virtual. A mobilidade do pensamento sempre esteve presente em nossas vidas na capacidade de refletir, informar e comunicar com as outras pessoas, a física possibilita-nos o deslocamento entre os diferentes lugares, e a informacional-virtual promove o acesso rápido e fácil ao fluxo de informações. Todas estão associadas, uma potencializando a outra, formando, juntas, uma mobilidade ampliada que se difunde nas múltiplas relações cotidianas.
} 
Segundo Cordeiro e Bonilla (2015), com a chegada da internet e do celular o conceito de mobilidade ganha novo significado e passa a ressignificar todas as relações sociais devido ao acesso instantâneo à comunicação e à possibilidade imediata de responder, participar, opinar sobre as mensagens e informações recebidas. Para as autoras é:

\begin{abstract}
A partir da revolução digital, da miniaturização de aparelhos e de sua conectividade com redes de comunicação, possibilitando misturar/articular o digital com o físico, criando um ambiente de tecnologia semântica e cognitiva, que começa a remodelar as nossas formas de fazer, criar, pensar e relacionar em nossa vida cotidiana, no trabalho, no lar, no lazer, na educação ou em qualquer espaço que possamos habitar (CORDEIRO; BONILLA, 2015, p. 262).
\end{abstract}

Concordamos com as autoras que as Tecnologias Digitais Móveis trouxeram uma nova dinâmica aos espaços (real e virtual), transformando os movimentos e as relações, porém, não podemos desconsiderar suas implicações nos diferentes contextos, em particular, no espaço escolar. As tecnologias móveis estão redefinindo as relações sociais e os sentidos de lugar (LEMOS, 2011) e na escola isso não ocorre de forma diferente.

Desse modo, a mobilidade deve ser problematizada, pois "[...] ela não é neutra e revela formas de poder, controle, monitoramento e vigilância, devendo ser lida como potência e desempenho" (LEMOS, 2011, p. 17), haja vista que:

Seu ar inofensivo é uma consequência deliberada da regra logística moderna que padroniza os movimentos, que elimina, o máximo possível, a estagnação. Mobilidade é adotada como padrão e passa a ser rotina. É nessa conexão entre visibilidade, padronização e rotina que se baseiam os movimentos dos bens globais. Ela tenta produzir estabilidade e previsibilidade e, assim, invisibilidade. (CRESSWELL, 2011, p. 87).

Afirma-se que a mobilidade cria uma relação complexa entre o espaço físico e o virtual de difícil percepção, pois esconde alguns movimentos contraditórios no curso das transformações sociais. Por isso, ela parece propícia à lógica de funcionamento da sociedade moderna, em razão do que Cresswel (2011) afirma ser a invisibilidade do processo basilar da produção social. Acredita-se que a mobilidade dada pelas tecnologias contribui para produzir o "invisível", visto que proporciona, durante os fluxos de informação, movimentos ocultos que "desaparecem" e "aparecem" nos diferentes momentos das relações. 
Junto a essa mobilidade, o espaço e o tempo são elementos que também devem ser problematizados, tendo em vista que as duas categorias (espaço-tempo) se transformam em suporte indispensável às formas de pensar, viver e produzir na contemporaneidade. Nesse sentido, a compreensão de ambos os termos são chaves para o cotidiano do homem.

Hoje, a mobilidade das relações representa fator indispensável ao desenvolvimento mundial, e isso somente é possível pela capacidade de o homem agir sobre o espaço e o tempo, sobre a natureza. Nesse sentido, espaço e tempo são elementos importantes, pois deles dependem as condições físicas para o capital mover-se aceleradamente.

Sendo assim, o capitalismo produzirá mudanças sempre que elas forem necessárias para a circulação de suas mercadorias. Por isso, o "tempo aniquila o espaço" como presumiu Marx, pois este, ao ser acelerado, satisfaz às condições lucrativas do mercado e destina-se, por meio da evolução dos meios de transporte e comunicação, a reduzir o processo de circulação da mercadoria. Ao capitalismo não importa a distância espacial que um produto percorre, mas a velocidade que determinado objeto leva para ser consumido.

Recentemente, com a inserção das tecnologias digitais na sociedade, há uma nova configuração social; nela, o espaço e o tempo passam a ser suprimidos pelas condições do "ciberespaço" 6 . São diversas as atividades possíveis, realizadas no mesmo lugar ou a quilômetros de distância; nelas entrelaçam-se os espaços (real/virtual) e anula-se o tempo, tendo em vista que as atividades podem ser realizadas no mesmo período de tempo. Transitar de um ambiente a outro, produzir, receber ou compartilhar informações, imagens, vídeos são algumas das possibilidades dessas ferramentas, quando conectadas à internet.

Infere-se que essa nova dinâmica social insere novos ritmos e formas à vida $\mathrm{e}$ à atividade produtiva do homem. Implica uma utilização diferenciada do espaço e do tempo, construindo novas formas de comunicação e relacionamento entre as pessoas. Nesse sentido, há, na contemporaneidade, uma forma diferenciada de produzir, vivenciar e perceber o espaço e o tempo, fruto do "novo" modelo de produção onde a

\footnotetext{
${ }^{6} \mathrm{O}$ ciberespaço é o novo meio de comunicação que surge da interconexão mundial dos computadores. O termo especifica não apenas a infraestrutura material da comunicação digital, mas também o universo oceânico de informações que ela abriga, assim como os seres humanos que navegam e alimentam esse universo (LÉVY, 1999, p. 16).
} 
informação e o conhecimento constituem eixos fundamentais para satisfazer às necessidades produtivas.

Desse modo, argumenta-se que as tecnologias digitais móveis junto à internet "[...] reconfiguram a trama de relações ao redor do globo de forma diversa e contraditória, afetando dinâmicas díspares e interdependentes (economia, política, educação e cultura)" (BASTOS, 2011, p. 55). Nessa reconfiguração, o homem não está preso ao ambiente físico, mas às novas possibilidades de interação trazidas pelas tecnologias.

Dessa maneira, torna-se essencialmente relevante compreender como a escola trabalha com essa dinâmica digital. Por isso, problematiza-se: em que medida as tecnologias digitais móveis entram em cena no contexto educacional? Até que ponto produzem novas maneiras de vivenciar o espaço-tempo? Como ocasionam mudanças nas relações, na comunicação, na prática pedagógica, enfim, nas dinâmicas do cotidiano escolar? É necessário compreender se as tecnologias transformam as formas, os ritmos e as modalidades da comunicação, da percepção e da produção do conhecimento.

Identifica-se a presença dos elementos tecnológicos no contexto educacional por meio de políticas públicas educacionais propostas pelos governos, ou trazidas do ambiente social para o meio escolar, pelos alunos, professores, coordenadores e gestores. Muitas vezes, são bem recebidas, noutras não, por isso, acabam ocasionando tensão no ambiente educativo. A escola tende a ignorar as ferramentas que não são enviadas pelo governo, porém, os alunos continuam insistindo em leválas para as salas de aulas, com maior frequência, o celular. A percepção é que esses recursos entram nas comunidades escolares e invadem um cotidiano que já tem seus próprios espaços-tempos delimitados, cronometrados, onde seus sujeitos possuem funções e tempos delimitados para estar na escola (CORDEIRO, 2014).

É imprescindível enfatizar que leis foram criadas para barrar o uso inadequado de algumas das tecnologias móveis no contexto educacional, mas elas acabam sendo burladas, pois os jovens não têm discernimento para saber quando se (des)conectar do mundo virtual. Assim, por meio dessas ferramentas, o cotidiano da escola passa a ser marcado por espaços e tempos diversificados, com uma "[...] dinâmica que mistura padronização e hierarquização de ritmos, conjuntamente com as possibilidades de negociação e alteração desses determinismos" (CORDEIRO, 2014, p. 116). 
Logo, a chegada dessas ferramentas à escola, principalmente, os smartphones, propõem refletir sobre o cotidiano escolar a partir da dualidade entre o presencial e o virtual, uma vez que esse parece ter sido transformado (CORDEIRO, 2014). Cordeiro analisa que o "[...] momento em que as tecnologias digitais móveis chegam às escolas elas já causam movimento no sentido da reorganização dos cotidianos escolares" (CORDEIRO, 2014, p. 296) e acrescenta ainda que "[...] há um movimento no sentido da desconstrução dos espaço-tempos lineares, alterando as relações e maneiras de produzir conhecimentos" (CORDEIRO, 2014, p. 287).

Para compreender esse contexto nos embasamos em Lemos (2007) e no seu conceito de "territórios informacionais", elaborado após a expansão das tecnologias de informação sem fio, para caracterizar as interfaces comunicacionais entre o espaço eletrônico e o urbano. Trata-se de um território invisível, constituído entre a interseção do espaço físico e o eletrônico. Nele, vivemos a sensação da perda de território, de apagamentos das fronteiras, não sabemos mais qual o limite das relações. Desse modo, há um processo de desterritorialização "generalizado" e agravado pela presença das tecnologias móveis, mas, ao mesmo tempo, criamos também novas territorializações, novos movimentos, estabelecemos um fluxo constante de trocas de informações nos diferentes espaços (LEMOS, 2007).

Sendo assim, parece pertinente argumentar que as tecnologias estão reconfigurando as práticas comunicacionais nos diversos ambientes sociais, inclusive no educacional, haja vista que por meio delas, os alunos navegam, mesmo estando na sala de aula, em uma variedade de páginas virtuais e aplicativos, mostrando que há diferentes formas de pensar, estar, ser, conviver, relacionar, interagir e aprender. As tecnologias digitais móveis, como afirma Lemos (2007), "reterritorializam" o espaço escolar, porém, ainda não podemos afirmar com clareza que tais meios são objetos propulsores de ensino e aprendizagem, uma vez que, na atual sociedade, elas são usadas, com maior grau de intensidade para reproduzir informação. Inseri-las com propósitos educacionais requer um debate profundo sobre quais possibilidades e limites trazem à educação.

Há de se concordar com Cordeiro (2014) que a tecnologia digital, em sua dimensão de mobilidade, cria espaços-tempos que "colocam na berlinda" a organização espaço-temporal da escola. O cotidiano educativo amplia-se e é alterado com a inserção de tais elementos, pois, por meio deles, os alunos criam novas formas de se relacionar, trocar informações e compartilhar conteúdo. Portanto, em uma 
dinâmica mais fluida, alunos e professores vão criando novas formas de habitar o espaço-tempo escolar, mesmo estando em contextos diferentes.

Desse modo, é preciso compreender o papel que as tecnologias digitais móveis assumem na educação, sem perder de vista todos os efeitos causados por essa interatividade. A reflexão sobre mobilidade, tempos e espaços proporcionados pelo uso digital tecnológico indica que é necessário ampliar a realização de estudos e pesquisas sobre a temática, que ainda está em construção no Brasil. Novos estudos são fundamentais para compreender os desafios e encontrar possíveis caminhos para o uso pedagógico das tecnologias digitais móveis no campo educacional, pois, por meio delas, pode-se identificar as mediações e possibilidades de criação de novos tempos e espaços de aprendizagem nas escolas.

\section{Vivências e trabalho docente no contexto educacional amazônico/PA}

As análises sobre a inserção das tecnologias digitais no contexto educacional amazônico e as vivências e trabalho docente apontam para a necessidade de se buscar outras formas de inserir tecnologias no ensino, formas estas que possibilitem driblar a lógica empresarial posta à educação e criar espaços em que prevaleçam ações realmente pedagógicas, que considerem a formação do sujeito em seus múltiplos aspectos e os levem a refletir, questionar, problematizar e identificar os anseios de inserir recursos tecnológicos na escola.

Mas, para que isso ocorra, é imprescindível que a tecnologia seja analisada e interpretada de forma crítica, sob a proposição de desvendar os anseios históricos e sociais que cercam a produção tecnológica nessa sociedade. Os relatos docentes expõem exaustivamente essa contradição, evidenciando que o uso do celular na escola pode contribuir com o processo educativo, mas também ocasionar alguns problemas.

Eu acho, que quando ele é utilizado de forma para a gente colocar o conteúdo para o aluno, ele vem ajudar muito. Agora, tem momentos que ele prejudica. A gente não tem controle. Aqui as nossas salas são todas superlotadas, então, a gente vai dizer que a gente tem domínio totalmente de sala? Eu posso dizer que uma hora ou outra algum aluno vai pegar. Aí, o que que a gente faz? Pede para eles pararem de utilizar. É isso que a gente pode fazer. A gente não pode estar arrancando celular, pegando celular, a gente fala que não pode trazer celular para dentro da sala de aula (PROFESSORA P1). 
Eu acho assim, para mim, o celular contribui. Ele causa problema quando eu não consigo frear o limite para o que é permitido ou não. [...] Para mim, ele traz mais consequências positivas do que negativas. Não que não apareçam as negativas. Aparecem. Porque num momento que é para eles discutirem num grupo, um ou outro aluno está ali conversando no WhatsApp [...] Mas aí, até nesse ponto a gente perceber que o nosso aluno está utilizando de maneira errada é pra que isso aconteça pra que a gente possa orientá-los no que é possível de acordo com aquele contexto ali da situação de como usar o celular. [...] Mas, é o risco que a gente assume, né! (PROFESSORA P2).

Essa é uma grande pergunta, porque se o celular... eu, como professor, para mim trouxe grande avanço. Porque se você precisar, opa! Vamos aqui [no celular] tirar a dúvida. Porém, para o alunado talvez como eles não têm a noção de como utilizar, talvez, atrapalhe, provavelmente, atrapalha (PROFESSOR P4).

Olha, eu fico em dúvida. Eu não falo que trouxe mais problemas, porque uma inovação tecnológica, ela tem os pontos positivos. Ela depende de como se utiliza e como se conversa com o aluno para usar ou não essa metodologia em sala de aula (PROFESSORA P6).

As falas reforçam o posicionamento de Selwyn (2017) sobre o uso das tecnologias na educação, ao demonstrarem que o celular, enquanto recurso pedagógico, não é um problema à educação, mas seu uso é problemático, pois depende da forma como é operacionalizado e dos anseios que rodeiam sua introdução na prática pedagógica. As opiniões corroboram a ideia de que o uso do celular de forma orientada pode ser aliado ao processo educativo, mas, do contrário, pode prejudicar alunos e professores quando desvia o foco das atividades pedagógicas.

É curioso, nos relatos, saber que os docentes afirmam ser o celular uma situação-problema apenas para os alunos, mas não para os professores, pois, segundo a categoria, os docentes têm propriedade para manusear a ferramenta, já os alunos "[...] não têm a noção de como utilizar" (PROFESSOR P4). Nesse sentido, é necessário frisar, e os depoimentos evidenciam isso, a importância de os usos das tecnologias digitais móveis na educação serem mediados e planejados para que todos tenham uma formação crítica sobre as ferramentas tecnológicas.

Os depoimentos apontam a ambiguidade da tecnologia na educação e reforçam a contradição que as ferramentas tecnológicas assumem na sociedade capitalista. O caráter dialético apresenta-se, quando os docentes argumentam que o celular pode trazer consequências positivas, mas também negativas à ação humana de educar. Desse modo, é importante reafirmar que a análise da tecnologia deve 
começar pelo modo como as pessoas se apropriam dos aparatos tecnológicos nos diferentes ambientes sociais.

Esse aspecto ambivalente da tecnologia é que permite interpretar as possibilidades e os limites do uso tecnológico na educação, isso porque, segundo Vieira Pinto (2005), na sociedade capitalista, essas ferramentas, na maioria das vezes, assumem uma dupla função: por um lado, elas podem operar dentro das relações sociais humanizadas, mas, por outro, podem estar a serviço de outros interesses. Porém, que fique claro, o aprisionamento não está nas tecnologias, mas sim nas estruturas sociais e econômicas em que estão imersas e acabam sendo inscritas em sua materialidade.

Desse modo, pode-se inferir que a problemática está relacionada à maneira como se dá o uso dessa tecnologia na sala de aula, já que os alunos têm "acesso" e fazem uso do celular no espaço escolar. Esse uso, pessoal ou pedagógico, ocasiona desdobramentos ao processo educativo dos alunos e está condicionado a aspectos favoráveis e desfavoráveis do ensino-aprendizagem. Os depoimentos, a seguir, são pertinentes e retratam as consequências desse uso durante as aulas.

Os meus alunos, quando vão me dar um texto, são todos médicos. A grafia deles é terrível, então, quando a gente termina de preencher o quadro eles falam: pera aí professor! Aí eles vão e batem foto e estudam por aquilo. Então, eles já não têm o hábito de estar escrevendo. [...] A grafia é ruim, a gramática é terrível, a acentuação [...] e geralmente, esses alunos que ficam mexendo no celular são os que têm as piores notas, porque eles se distraem muito com aquilo. Agora, ontem eu passei uma recuperação para uma turma e uma aluna [...] além de tirar vermelho, a nota é muito baixa, porque ela senta no canto, coloca a bolsa e pega o celular (PROFESSOR P4).

Eu observo que eles não prestam muita atenção na explicação nas aulas, as notas deles diminuem [...] têm muitos que têm nota baixa. A minha disciplina com eles é arte e têm muito dois, três, cinco e meio [...] eles pensam que artes é fácil e por conta disso não prestam atenção. Conversar pessoalmente eles conversam pouco, mas no celular eles ficam bastante $e$ isso atrapalha o rendimento deles (PROFESSORA P6).

Porque eles acabam não tendo atenção total para aula, ficam assim desligados e querem ver o celular, aí alguns acabam vendo mesmo e aí a gente chama atenção, às vezes, fica um clima até desagradável, às vezes, existem problemas quando realmente a gente chama atenção e tira o celular deles. Existe essa política também, na maioria das escolas como é proibido na sala de aula, quando não se tem um fim pedagógico, de retirar de levar para coordenação, pra direção. 
Então, tem todo um transtorno aí. Mas, a falta de interesse é só reforçada pelo uso do celular (PROFESSOR P8).

Ao que se pode averiguar pelos depoimentos, o uso do celular na sala de aula causa sérias implicações ao processo de ensino-aprendizagem dos alunos. Os professores evidenciam em suas falas que o uso da tecnologia resulta em processos inconvenientes à relação professor-aluno, provoca falta de atenção nas aulas, atrapalha o rendimento e ocasiona notas baixas, modifica a grafia (devido à ausência da escrita) e transforma as formas de comunicação entre os sujeitos.

Os usos diversos que os alunos fazem dessa tecnologia ocasiona tensão ao espaço educativo pelas outras maneiras de estar, ser e se comunicar (CORDEIRO, 2014). Há uma dualidade sobre o que se passa na escola e o contexto compartilhado nas redes, pois esses sujeitos não almejam ficar desconectados dos acontecimentos à sua volta e continuam manuseando suas tecnologias móveis no espaço escolar. A distração é resultado desse intenso "convívio" digital, que está ancorado nas inúmeras notificações que chegam instantaneamente nos aparelhos celulares dos alunos.

Consequentemente, esse uso acaba causando desordem, como é evidenciado no relato do Professor P8: "[...] fica um clima até desagradável, às vezes, existem problemas quando realmente a gente chama atenção e tira o celular deles", e reforça o uso do autoritarismo (MARTíN, 2014), quando retira, contra a vontade dos alunos, suas tecnologias pessoais. O clima desagradável, exposto pelo professor P8, surge dessa oposição de vontades e se converge em uma maior repressão por parte da direção e dos professores sobre os alunos, que, timidamente, recolhem suas ferramentas para utilizarem em momentos mais "calmos".

Outra consequência destacada nos depoimentos refere-se à falta de atenção nas aulas, que resulta na redução do desempenho do aluno nas aulas e em notas baixas. Kobs (2017) aponta, em sua tese, que um maior uso dos dispositivos móveis reflete em uma ligeira redução na nota, motivado pelo pouco aproveitamento dos dispositivos no processo de ensino-aprendizagem. A descoberta pode estar relacionada ao fato de os adolescentes utilizarem seus dispositivos móveis, sobretudo para o lazer, e pouco para pesquisas em assuntos pertinentes ao conteúdo escolar.

Uma terceira implicação, destacada pelo Professor P4 está relacionada à grafia dos alunos. É perceptível, no depoimento do docente, que o uso da tecnologia converge para o empobrecimento da escrita dos jovens, pois costumam utilizar suas tecnologias nos diversos momentos da aula, deixando de escrever as atividades para 
registrá-las em imagem fotográfica. A digitalização, a mobilidade, a possibilidade de armazenamento e o acesso momentâneo à informação corroboram para que os estudantes deixem de lado o papel e a caneta e utilizem seus smartphones para "guardar" conteúdo escolar.

Por outro lado, a resposta do Professor P4 e da Professora P6 permite pensar que o contexto vivido nas escolas está sendo transformado por novos hábitos comunicacionais que valorizam o aspecto digital e a mobilidade das informações, deixando de lado a oralidade e a escrita. Essas ferramentas, conforme o relato docente, ao adentrarem o espaço da sala de aula, começam a influenciar a forma como os alunos lidam com as informações veiculadas nesse espaço, como as armazenam para consultas posteriores e como estudam, pois, como afirma o Professor P4, "[...] quando a gente termina de preencher o quadro eles [...] vão e batem foto e estudam por aquilo".

Observa-se que a introdução do aparelho celular na escola possibilitou um novo modo de lidar com as informações recebidas na sala de aula, onde o acesso aos conteúdos trabalhados ocorre de maneira imediata e instantânea. Entende-se, assim como Subtil (2013, p. 408), que essa realidade "[...] propõe um novo significado aos momentos do processo comunicacional - produção, circulação e recepção enfatizando as tecnologias por suas características mediadoras que modificam o emissor, o receptor e a mensagem". Evidentemente que tais mudanças não ocorrem por acaso, pois estão ligadas a um contexto maior e têm como pano de fundo a estrutura econômica que determina o grau e as mudanças que devem ocorrer na sociedade.

Corroboramos o pensamento de Subtil (2013) acerca dessas considerações que nos alertam, enquanto educadores, para o fato de que nossos espaços escolares estão sendo bombardeados pelos avanços tecnológicos e neles estão presentes as diferentes possibilidades de oralidade, escrita e interação que hoje conectam crianças, jovens e adultos mundo afora. Assim, se levarmos em consideração essas mudanças, não de forma absoluta, mas contextualizando-as e atribuindo a elas sentido pedagógico, pode-se afirmar que professores devem se voltar para o estudo e para a formação em tempos de tecnologias informacionais.

Nosso grande desafio, hoje, é fazer com que essas informações digitais, que chegam até nossos alunos, não sejam simplesmente armazenadas em seus dispositivos móveis e compartilhadas intencionalmente, mas que sejam apropriadas e 
transformadas em conhecimento sobre a realidade em que estão inseridos. Para isso, características pedagógicas devem ser pensadas de modo a potencializar, não somente o trabalho docente, mas que possibilitem o uso crítico e criativo da tecnologia (PRAZERES, 2016).

Ao examinar o espaço-tempo das escolas, a partir da inserção das tecnologias digitais móveis, identificou-se que a tecnologia vem interferindo nas relações, na forma de comunicação e facilitando o diálogo entre as categorias investigadas, conforme apresentado nos depoimentos a seguir:

O que eles não têm coragem de falar para gente presencial, eles passam mensagem: "Professora, eu não entendi sua aula hoje. Teria como a senhora me passar algum link de algum material pra estudar?" Eu recebo muitas mensagens, então, assim, a relação professor-aluno teve uma aproximação maior (PROFESSORA P1).

Sim, principalmente, pelo WhatsApp: a gente cria grupos quando tem algum trabalho específico, [por exemplo] quando teve a gincana da escola. Então, através do grupo, como a gente não tem tempo de se reunir, aí a gente decide as ações pra planejar como é que a gente vai fazer. Então, fica mais fácil essa conversa a distância (PROFESSORA P5, grifos nossos).

É visível nos depoimentos que o adentramento do celular na escola rompeu com a barreira física de se estar no espaço escolar para manter o diálogo, tirar dúvidas, questionar e solicitar conteúdo aos professores. Os limites demarcados pelos muros escolares foram ultrapassados e, a qualquer momento, com uma "simples" mensagem, o aluno pode solicitar informações ao docente e o docente, ao aluno. Pelo exposto, essa interação é frequentemente utilizada, como relatam as Professoras P1 e P5.

Assim, observa-se que, após a inserção das tecnologias digitais móveis na escola, professores e alunos deixaram de estar presos a tempos e espaços fixos e começaram a "navegar" pelas novas possibilidades trazidas pelos aparatos tecnológicos. Houve uma mudança significativa nas práticas de comunicação, convivência e interação entre os sujeitos, desencadeando reflexos no ato educativo. O momento aula deixou de ser o único lugar onde alunos e professores trocavam informações. A tecnologia possibilitou criar um ambiente remoto, onde a escola possui vínculos invisíveis com outros espaços. Os sujeitos que nela frequentam dão vida e movimento a essas conexões, por meio das formas que interagem e alimentam esses 
espaços. Os conteúdos envolvidos variam e são transmitidos constantemente por trocas de mensagens, fotos, vídeos e documentos compartilhados ou recebidos.

Cordeiro (2014), ao analisar o espaço-tempo da escola com a chegada das tecnologias digitais móveis, avalia que esse território foi alterado e novos espaçostempos de comunicação e interação foram criados pelos jovens, gerando uma multiplicidade espaço-temporal nesse ambiente. Para a autora, são espaços e tempos híbridos que "colocam na berlinda" a organização da escola, pois, ao mesmo tempo em que os alunos estão enviando mensagens ou entrando nas redes sociais, estão tirando foto do conteúdo que o professor passou no quadro ou realizando pesquisas sobre os conteúdos trabalhados em sala.

A presença crescente da tecnologia digital no cotidiano é, assim, vista como algo que derruba barreiras tradicionais entre lugar/espaço; produção/consumo; atos isolados/simultâneos; tempo síncrono/assíncrono; indivíduos/instituições (SELWYN, 2017). Observa-se, portanto, que o espaço-tempo da escola está sendo expandido para além da sala de aula, para outros espaços-tempos, podendo chegar tanto nas residências dos alunos quanto em qualquer outro espaço onde possam estar com seus celulares, tirando dúvidas ou trocando ideias e informações em rede.

A narrativa da professora parece acenar nessa direção:

Eu tenho uma equipe que tá produzindo o vídeo sobre regência não verbal e elas estão mandando vários vídeos pra ver se tá bom, se é assim para eles fazerem, então, olha como é interessante, né. A menina está aonde? Não sei. Elas podem estar lá no grupo de discussão sobre o trabalho e eu estou aqui num outro ambiente e eu posso dar assistência para elas. E o resultado do trabalho delas vai sair mais produtivo do que se, por exemplo, eu não tivesse o celular pra gente se comunicar. Então, olha como é fantástico! (PROFESSORA P2).

Verifica-se que uma nova interface é criada entre zona real-virtual, para a realização de atividades escolares e ampliação da comunicação entre professor-aluno e vice-versa. Nessa interconexão, mora uma nova forma de construção de saberes e conhecimentos que não se dá no ambiente escolar pela "timidez do aluno" (PROFESSORA P1) e das formas que a escola trabalha com esse recurso, negandoo na maioria das vezes. A tecnologia, nesse caso, possibilita que o ensino e a aprendizagem se prolonguem para além do ambiente escolar.

Contudo, cabe enfatizar que a ação informada pela docente não faz parte de uma prática orientada, mas despretensiosa que "[...] se dá nas fendas, entre aqueles 
praticantes mais inteirados que entram nas redes e chamam o professor, que perguntam, que buscam estabelecer essa relação fora do espaço formal da escola" (CORDEIRO, 2014, p. 230). Pelo relato da docente, o uso da ferramenta tecnológica apresenta-se como uma possibilidade de interação pedagógica sobre o trabalho escolar, porém observa-se que a atividade parte de ações fragmentadas e individualizadas que se dão a partir de iniciativas solitárias dos alunos.

A simples orientação seletiva atribuída pelo professor a um ou dois grupos de alunos não é suficiente para que esse ato se efetive como prática pedagógica. É preciso, acima de tudo, que essas atividades tenham intencionalidade pedagógica e se desenvolvam a partir de ações planejadas orientadas a atingir objetivos. Além disso, é necessário que o processo de interação atenda a todos os sujeitos envolvidos no ato educativo e não somente aos que solicitarem ajuda. A mediação aqui é instrumento central para tornar possível o processo educativo e atribuir dimensão pedagógica ao uso tecnológico, isso porque a lógica de uso da tecnologia no ensino deve fugir do mero consumo de informações.

Portanto, há de se ter o cuidado de "[...] não estender o conceito de mediação a pura utilização do recurso ou mesmo a mediação dependente do recurso, depositando no recurso tecnológico a capacidade de mediação que deve ser depositada no sujeito como meio social” (BUENO, 2013, p. 304). Para Bueno (2013), deve-se colocar o sujeito professor no centro do processo de mediação, não o instrumento máquina, considerando o trabalho pedagógico como forma de mediação, e não o instrumento, a máquina. A autora deixa claro que a máquina jamais deve ser o centro em uma relação com uso de instrumentos tecnológicos. Ela deve ser vista, desse modo, como um ator coadjuvante, que interage com os demais personagens para compor uma cena, mas tendo como principal protagonista o homem.

Considerando as novas possibilidades de comunicação e interação, os dados indicam que o celular é um importante instrumento para a escola. O que não parece claro para os sujeitos são os usos pedagógicos dessa ferramenta na educação, as implicações dos processos digitais na aprendizagem, no ensino, na construção do conhecimento, como lidar com as relações tecidas por meio desses aparelhos e como ter o autocontrole sobre o tempo e espaço de uso no que se refere à hora de enviar ou de responder mensagens, acessar redes sociais, compartilhar arquivos, dentre outras atividades possíveis. De todo modo, não se pode negar a positividade desse 
meio comunicativo, mas há a necessidade de questionar sua inserção nas relações educativas.

$\mathrm{Na}$ escola, a inserção do aparelho móvel pessoal e as novas relações projetadas em rede, por via dele, estão sendo inseridas não só entre professores e alunos, mas nas diversas relações tecidas nesse ambiente, como evidencia o depoimento a seguir:

A gente tem na escola o grupo de WhatsApp. Inclusive eu fui descobrir que têm vários grupos. Tem o grupo só dos professores, só dos coordenadores, só dos diretores, então, para você ver só o nível de relação que o celular proporciona. [...] Ora, nós temos grupos de WhatsApp que é aonde a gente sabe que vai ter reunião, que é quando a gente sabe que vai ser um simulado, porque não dá para o diretor reunir todo mundo ao mesmo tempo numa sala. Por exemplo, quando tem reunião sempre falta um, dois, três e no grupo de WhatsApp ele põe uma informação e todo mundo fica sabendo da informação. [...] Então, eu acho assim, que há essa interação e isso acaba repercutindo em nossa sala de aula (PROFESSORA P3).

A presencialidade deixou de ser um fato necessário para efetuar determinadas atividades da escola e o mundo digital passou a influenciar no trabalho e nas formas de relacionamento interpessoal dentro da escola. Veja que a fala docente expõe traços significativos de como o ambiente virtual está adentrando o contexto escolar e transformando o espaço de trabalho, o tempo em que se realizam as atividades e as relações, incluindo aqui as reuniões periódicas realizadas entre os diferentes grupos de profissionais e os vínculos pessoais entre os funcionários. Dessa forma, a rede comunicativa criada entre os agentes escolares passa a permitir que o trabalho realizado no espaço físico da escola vá além do momento presencial e ultrapasse os limites espaço-temporais da escola.

Os grupos criados em rede permitem que a escola e o trabalho nela realizado se reproduzam em outros espaços e tempos, o que demonstra que a rotina escolar foi metamorfoseada para estar além do espaço físico, e tempo e espaço foram modificados ou reeditados a partir da inserção da tecnologia móvel. Há, portanto, a desconstrução dos espaço-tempos lineares e a construção de "novas" relações e maneiras de produzir conhecimento (CORDEIRO, 2014) e trabalho. Porém, cabe-nos questionar até que ponto essa nova relação está contribuindo com o desenvolvimento das atividades escolares. 
As narrativas docentes expõem claramente que a tecnologia digital móvel permite criar uma "nova" dinâmica escolar que influencia na forma de comunicação e no relacionamento professor-aluno, aluno-professor e demais categorias profissionais que compõem o núcleo escolar, mas, de outro lado, invisibilizam, pelas positividades enfatizadas, outras relações tecidas nos espaços-tempos real/virtual. As diferentes situações vividas na escola são exteriorizadas pelo ambiente virtual, que amplifica a rotina escolar para além do que é estabelecido. Com isso, a relação real-virtual cria uma ruptura da linha divisória entre tempos e espaços de produção e reprodução das tarefas/atividades escolares, levando o trabalhador professor a não saber ao certo onde começa e onde termina seu tempo de trabalho. Essa avaliação permite crer que tempo e espaço de trabalho docente são rarefeitos pela dinâmica digital.

Assim, em tempos de tecnologias digitais e móveis, o celular e a sua fábrica de aplicativos têm-se mostrado excelentes meios de intensificação da jornada de trabalho, quando nenhum trabalhador prescinde viver sem essa tecnologia. Desta feita, torna-se relevante analisar o trabalho docente como inserido em uma totalidade maior, ou seja, no contexto da reestruturação produtiva do capital, que vem sendo implementada desde a década de 1970 e tem forte repercussão no trabalho e na formação docente. Ressalta-se que esse processo tem relação direta com a nova morfologia do trabalho, a qual exige um trabalhador "polivalente e multifuncional", alinhado com as perspectivas da Sociedade do Conhecimento. (ANTUNES, 2008).

Não há dúvida de que o trabalho docente é afetado, em cheio, por essas mudanças, que forçam o ritmo da produção, incrementam as tarefas a serem realizadas, instituem horários atípicos, com aceleração no desempenho das atividades e 0 aprofundamento de uma dinâmica produtivista-consumista. (MANCEBO; MAUÉS; CHAVES, 2006). Em consequência da adoção das perspectivas gerenciais no campo da educação, ocorre uma naturalização dos princípios neoliberais e capitalistas, em detrimento da formação humana.

As condições comunicativas da sociedade atual reforçam a necessidade da comunicação instantânea e implicam que trabalhadores e trabalhadoras fiquem conectados a seus trabalhos mais de oito horas por dia. No caso do espaço escolar, há uma ausência de tempo livre quando afirma que "para dar conta de tudo, fazemos no presencial e no virtual". (PROFESSORA P5; P4).

Fidalgo, Oliveira e Fidalgo (2009) analisam o trabalho docente, frente às novas exigências do processo de globalização e a reestruturação tecnológica de produção e 
seus desdobramentos na educação, retratando que a profissão docente sofre impactos e intervenções a partir dessa nova configuração social que afeta diretamente em sua forma de trabalho, uma vez que são obrigados a se adequar e a incorporar habilidades e competências ao manuseio das TICs em sua atividade laboral. Esse processo, segundo os autores, ocasiona algumas consequências à profissão docente, entre elas, a intensificação do trabalho relacionada principalmente à sobrecarga de trabalho difundida pela falta de tempo dos professores para exercer determinadas atividades escolares.

Além disso, Antunes (2018) afirma, ao realizar um apanhado fotográfico sobre o trabalho na sociedade digitalizada e tecnologizada, que está florescendo uma nova era de trabalho precário escamoteada pelo trabalho on-line e digital. O autor apresenta um mosaico excepcional do mundo do trabalho real na era do trabalho virtual, expondo experiências de trabalho excessivo nas empresas de fabricação de smartphones e seus assemelhados e conclui que as tantas cenas presentes no universo do trabalho fazem desmoronar um labor invisibilizado que floresce em uma nova modalidade de trabalho: o escravo digital.

Em meio a essa nova formatação do trabalho, novas formas de exploração surgem para atender às particularidades do universo informatizado e evidencia, claramente, o que Marx assinalava, em meados do século XIX:

O que diferencia as épocas econômicas não é "o que" é produzido, mas "como", "com que meios de trabalho". Estes não apenas fornecem uma medida do grau de desenvolvimento da força de trabalho, mas também indicam as condições sociais nas quais se trabalha (MARX, 2013, p. 257).

Nessa passagem, Marx salienta que a transformação do trabalho e dos meios de trabalho tem consequências diretas às condições sociais, assim como estas têm para os processos de produção. Isso significa que, se as condições sociais mudam, mudam com elas os instrumentos e as formas de trabalho, e vice-versa. Logo, à medida que a sociedade é transformada, transformam-se com ela as tecnologias e, junto a essa transformação tecnológica, também se transformam as relações sociais.

Esse recorte, extraído do livro primeiro d'O Capital, é pontual e, surpreendentemente, elucida como o avanço tecnológico segue as tendências da transformação histórico-social e, como essa mutação atua na incrementação de novas formas de trabalho e na criação de meios de produção. Portanto, há uma relação 
dialética que se desenvolve de forma mútua, onde ambos necessitam um do outro para proliferarem. Entretanto, esses avanços não se dão por acaso, ao contrário, acompanham a escala de desenvolvimento vigente para atingir a determinados interesses gerados pelo sistema sociometabólico do capital.

Dessa forma, na era das tecnologias digitais móveis, o processo de trabalho docente está sendo ressignificado e, com ele, as formas de extração de mais trabalho para atender às novas demandas capitais. Antunes (2018, p. 44) argumenta que atualmente estamos presenciando "[...] o advento de novas formas de extração do mais-valor também nas esferas da produção não material", tendo nas TICs seu flagelo-motor. Essas novas engrenagens reproduzidas pelo capitalismo informatizado, ao contrário da eliminação completa do trabalho pelo maquinário informacional-digital, estão levando ao extremo os níveis de superexploração da classe trabalhadora.

Na perspectiva de Frigotto (2006, p. 134) isso ocorre porque a ideia básica é que o capital "no seu processo de acumulação, concentração e centralização pelo trabalho produtivo vai exigindo cada vez mais, contraditoriamente, trabalho improdutivo, como se fossem verso e anverso de uma mesma medalha". Para o autor, a improdutividade da escola constitui uma mediação necessária e produtiva para a manutenção das relações capitalistas de produção criando, portanto, vínculos da educação com a estrutura econômico-social capitalista.

A abordagem apontada por Frigotto expõe a necessidade de conhecer a caracterização das diferentes formas de trabalho e de trabalhador na divisão social do trabalho, tomando como fundamento as diferentes configurações da sociedade em discussão, pois é essa última que desenha as múltiplas formas de trabalho na fábrica ou em qualquer outro setor do sistema produtivo. Esse processo, que tem como resultante uma crescente inter-relação entre trabalho material e imaterial, parece indicar uma necessária complementaridade entre ambos em uma mesma totalidade na visão do trabalho e do trabalhador coletivo.

Pelo que foi exposto até aqui, a inserção de tecnologias digitais móveis na escola não está desarticulada do âmbito social e nos oferece pistas pertinentes do porquê o espaço escolar e o trabalho docente estão sendo submetidos a questões comunicacionais/informacionais mediadas por modernos instrumentos tecnológicos. Se, por um lado, os smartphones possibilitam uma melhor comunicação e interação entre os agentes escolares, por outro, deve ser considerado como produtor de mais trabalho, ao intensificar a carga horária de labor docente e fazer com que os 
professores disponham de seu "tempo livre" para continuar resolvendo questões relacionadas à escola, porém, esse tempo extra de trabalho digital não é pago, é trabalho excedente.

Nosso desafio, enquanto educadores, é desvendar essa rede de relação complexa, cercada por grupos de interesses políticos e econômicos, para pensar formas outras de apropriação das tecnologias digitais móveis na educação. Nesse sentido, antes de utilizá-la em qualquer ato educativo, é imprescindível levantar a natureza política da relação educação e tecnologia, para refletir "como" e "por que" tecnologias estão sendo usadas em contextos educacionais. Vista por esse prisma, essas inovações, ao serem introduzidas na escola, requerem um exame crítico sustentado com análises mais detalhadas e ricas sobre os aspectos positivos, negativos a toda e qualquer nuance intermediária (SELWYN, 2017).

Desse modo, é imprescindível uma análise mais criteriosa dos recursos tecnológicos na educação com o propósito de desvendar a conexão dessas máquinas com o contexto mais amplo e com o modo de produção capitalista, pois é desvelando a lógica incorporada nessas máquinas e seus elementos históricos e sociais que se pode pensar na superação das condições materiais e na possibilidade de contribuição ao ensino.

\section{Considerações finais}

As análises realizadas apontam para a necessidade de superação da lógica instrumentalizada das tecnologias na sociedade e na escola. No campo das relações, evidenciou-se que o celular transforma o ritmo e as modalidades de comunicação e interação na escola, propondo pensar o cotidiano escolar entre o ambiente presencial e o virtual. As análises apontam que, muito embora o uso do aparelho celular seja proibido nas escolas estaduais, ele vem criando e alterando as formas que aluno/aluna e professor/professora se relacionam um com o outro e com a informação e o conhecimento.

As análises encaminham, então, para a constatação de que, após a inserção das tecnologias digitais móveis na escola, professores e alunos/alunas deixaram de estar presos a tempos e espaços fixos; começam a "navegar" pelas novas possibilidades trazidas pelos aparatos tecnológicos para trocar informações e conteúdos. As análises permitem constatar ainda que o momento da aula deixou de 
ser o único lugar onde esses sujeitos trocam informações, uma vez que a tecnologia possibilitou criar um ambiente remoto entre a escola e os outros espaços. Nesse ambiente invisível, são os sujeitos que dão vida e movimento a essas conexões, por meio das formas que interagem e alimentam esses espaços. Os conteúdos envolvidos variam e são transmitidos ou recebidos, constantemente, por trocas de mensagens, fotos, áudios, vídeos e documentos compartilhados.

Os dados possibilitam constatar, portanto, que o espaço-tempo da escola está sendo expandido para além da sala de aula, para outros espaços-tempos onde o aluno/aluna ou professor/professora possa estar conectado tirando dúvidas ou trocando informações em rede. Verifica-se, assim, que uma nova interface é criada, entre zona virtual e real, para a realização de atividades escolares e ampliação da comunicação entre professor-aluno e aluno-professor. Nessa interconexão, mora uma nova forma de construção de saberes e conhecimentos que não se dá no ambiente escolar pela "timidez do aluno" e pelas formas que a escola trabalha com esse recurso, negando-o, na maioria das vezes. A tecnologia, nesse caso, possibilita que o ensino e a aprendizagem se prolonguem para além do ambiente escolar.

Observa-se, ainda, que essa transformação se espalha também sobre as demais relações desenvolvidas na escola e no trabalho docente. Através das análises, identifica-se que a presencialidade deixa de ser um fato necessário para efetuar determinadas atividades da escola e o mundo digital passa a influenciar no trabalho e no espaço-tempo em que se realizam, nas relações entre gestão, coordenação, professores e alunos, incluindo aqui as reuniões periódicas realizadas entre os diferentes grupos de profissionais e os vínculos pessoais entre os funcionários.

No âmbito do trabalho docente, as análises realizadas possibilitam constatar que a rede comunicativa criada entre os agentes escolares, por meio de aplicativos de mensagem instantânea, permite que o trabalho realizado no espaço físico da escola vá além do momento presencial e ultrapasse os limites espaço-temporais da escola. Os grupos criados em rede possibilitam que a escola e o trabalho nela realizado se reproduzam em outros espaços e tempos, o que demonstra que a rotina escolar foi metamorfoseada para estar além do espaço físico e tempo/espaço foram modificados ou reeditados a partir da inserção da tecnologia móvel pessoal.

É interessante pontuar que apesar das inúmeras possibilidades criadas pela inserção das TICs no cotidiano escolar, elas ocorrem no contexto de reestruturação produtiva do capital onde a intensificação do trabalho tem sido uma estratégia adotada 
pelo capital para aumento de suas taxas de lucro. Por outro lado, o trabalho docente também vem sendo intensificado onde passa-se a exigir novas competências e habilidades à profissão docente. Tais análises evidenciam os sérios desafios a serem enfrentados pelos sujeitos, no contexto escolar brasileiro e amazônico.

\section{Referências}

ANTUNES, R. O privilégio da servidão: o novo proletariado de serviços na era digital. São Paulo: Boitempo, 2018.

Afinal quem é a classe trabalhadora hoje? Revista da Rede de Estudos do Trabalho, n. 3, p. 1-9, 2008. Disponível em: <http://marxismo21.org/wp-content/uploads/ 2014/02/Trabalhadores-RicardoAntunes-Afinal-quem-e-a-classe-trabalhadora-hoje.pdf>. Acesso em: 12 set. 2015.

BALBIM, R. Mobilidade: uma abordagem sistêmica. In: BALBIM, R.; KRAUSE, C.; LINKE, C. C. (org.). Cidade e movimento: mobilidades e interações no desenvolvimento Urbano. Brasília: Ipea-ITDP, 2016. Disponível em: http://www.ipea.gov.br/ portal/index.php?option=com_content\&view=article\&id=28489. Acesso em: 01 maio 2018, 08:54.

BASTOS, M. Algumas notas sobre economia num mundo de geografias celulares. In: BEIGUELMAN, G.; LA FERLA, J. (org.). Nomadismos tecnológicos. São Paulo: Editora Senac, 2011.

BUENO, N. de L. Tecnologia educacional e reificação: uma abordagem crítica a partir de Marx e Lukács. 2013. 503 f. Tese (Doutorado em Educação) - Universidade Federal do Paraná, Curitiba.

CORDEIRO, S. de F. N. Tecnologias digitais móveis e cotidiano escolar: espaços-tempos de aprender. 310 f. 2014. Tese (Doutorado em Educação) - Faculdade de Educação, Universidade Federal da Bahia, Salvador.

; BONILLA, M. H. S. Tecnologias digitais móveis: reterritorialização dos cotidianos escolares. Educar em Revista, Curitiba, n. 56, p. 259-275, abr./jun. 2015. Disponível em: http://www.scielo.br/pdf/er/n56/0101-4358-er-5600259.pdf. Acesso em: 23 jan. 2018, 21:22.

CRESSWELL, Tim. A política da turbulência. In: BEIGUELMAN, Giselle; LA FERLA, Jorge (org.). Nomadismos tecnológicos. São Paulo: Editora Senac, 2011.

FIDALGO, F.; OLIVEIRA, M. A.; FIDALGO. N. L. Trabalho docente, formação continuada e tecnologias. In: FIDALGO, F.; OLIVEIRA, M. A.; FIDALGO. N. L. Intensificação do trabalho docente: tecnologias e produtividade. São Paulo: Papirus, 2009.

FRIGOTTO, G. A produtividade da escola improdutiva: um (re) exame das relações entre educação e estrutura econômico-social capitalista. 8ª edição. São Paulo: Cortez, 2006.

KOBS, F. F. Os possíveis efeitos do uso dos dispositivos móveis por adolescentes: análise de atores de uma escola pública e uma privada. 2017. 243 f. Tese (Doutorado em 
Tecnologia e Sociedade) - Programa de Pós-Graduação em Tecnologia e Sociedade, Universidade Tecnológica Federal do Paraná, Curitiba.

KOSIK, K. Dialética do Concreto. 7. ed. Rio de Janeiro: Paz e Terra, 2002.

LEMOS, A. Cibercultura como território recombinante. In: MARTINS, C. D; SILVA, D. C. e; MOTTA, R. (org.). Territórios recombinantes: arte e tecnologia. São Paulo: Instituto Sérgio Motta, $2007 . \quad$ p. 35-46. Disponível em: https://edumidiascomunidadesurda.files.wordpress.com/2016/05/andrc3a9-

lemoscibercultura-como-territc3b3rio-recombinante.pdf. Acesso em: 22 mar. 2018.

Cultura da mobilidade. In: BEIGUELMAN, G.; LA FERLA, J. (org.). Nomadismos tecnológicos. São Paulo: Editora Senac, 2011.

LÉVY, P. Cibercultura. São Paulo: Editora 34, 1999.

MANCEBO, D.; MAUÉS, O. C.; CHAVES, V. L. J. Crise e reforma do Estado e da Universidade Brasileira: implicações para o trabalho docente. Revista Educar, Curitiba, n. 28, p. 37-53, 2006. Disponível em: <http://www.scielo.br/pdf/er/n28/ a04n28>. Acesso em: 10 dez. 2014.

MARX, K. Contribuição à crítica da Economia Política. Tradução de Florestan Fernandes. 2. ed. São Paulo: Expressão Popular, 2008.

O Capital: Crítica da Economia política. Livro I. O processo de produção do Capital. Tradução: Rubens Enderle. São Paulo: Boitempo, 2013.

MARTÍN, L. da S. N. Entre a apropriação e a proibição: trânsito dos dispositivos móveis em escolas públicas. 2014. 145 f. Dissertação (Mestrado Interdisciplinar em Educação, Linguagem e Tecnologias) - Unidade de Ciências Sócio-Econômicas e Humanas, Universidade Estadual de Goiás, Anápolis, 2014.

MÉSZÁROS, I. A educação além do capital. Tradução de Isa Tavares. São Paulo: Boitempo, 2005.

SANTOS, M. Economia espacial: críticas e alternativas. 2. ed. São Paulo: Editora da Universidade de São Paulo, 2003.

Por uma geografia nova: da crítica a geografia a uma geografia crítica. 6 . ed. São Paulo: Editora da Universidade de São Paulo, 2004.

A natureza do espaço: técnica e tempo, razão e emoção. 4. ed. São Paulo: Editora da Universidade de São Paulo, 2006.

Para além do capital: Rumo a uma teoria da transição. Tradução de Paulo Cezar Castanheira e Sérgio Lessa. São Paulo: Boitempo, 2011.

PRAZERES, M. S. C. dos. O Programa Navega Pará como política pública de inclusão digital: implicações nas escolas públicas do Estado Pará, 2016. 274 f. Tese (Doutorado em Educação) - Universidade Estadual de Ponta Grossa, Ponta Grossa, PR.

SELWYN, N. O que queremos dizer com "educação" e "tecnologia"? In: SELWYN, Neil. Education an Tecnology: key issues and debates. Tradução: Giselle Martins dos Santos Ferreira. Londres: Bloomsbury, 2011. [Edição para Kindle]. Disponível em: https://ticpe.files.wordpress.com/2016/12/neil_selwyn_keyquestions_cap1_trad_pt_final1.pdf Acesso 11 nov. 2017, 19:23. 
Educação e tecnologia: questões críticas. In: FERREIRA, Giselle Martins dos Santos; ROSADO, Luiz Alexandre da Silva; CARVALHO, Jaciara de Sá. Educação e Tecnologia: abordagens críticas. Rio de Janeiro: SESES, 2017.

SUBTIL, M. J. D. Tecnologias e meios de comunicação na educação: a necessária reflexão sobre formação e trabalho docente. Revista HISTEDBR On-line, Campinas, n. 52, p. 402-415, set. 2013. Disponível em: http://www.revistas2.uepg.br/index.php. Acesso em: 25 abr. 2017.

VIEIRA PINTO, Á. O conceito de tecnologia. São Paulo: Contraponto, 2005. V.1. 